\title{
Nasyid music training for teenagers mosque in hamlet III pondok pasar 4 Damuli Kebun village Kualuh Selatan Labuhanbatu North Sumatra
}

\author{
Hubari Gulo $^{1^{*}}$, Alemina Br. Perangin-angin ${ }^{1}$, Agus Salim Harahap ${ }^{2}$ \\ ${ }^{1}$ Faculty of Cultural Sciences Universitas Sumatera Utara, Medan, Indonesia \\ ${ }^{2}$ Faculty of Math and Science Universitas Sumatera Utara, Medan, Indonesia \\ *Email: hubari@usu.ac.id
}

\begin{abstract}
Indonesia has many cultures, almost every region has a different culture and customs. Labuhanbatu Utara is one of the regions in North Sumatra that has 8 districts. In South Kualuh sub-district has a habit to sing nasyid on certain and special events. Nasyid is one of the Islamic arts in the field of sound art. Usually it is a song that has an Islamic style and contains words of advice, stories of the prophets, praising God, and the like. Nasyid is usually sung in a cappella accompanied by only a drum. Community service program in 2019 is real community empowerment with the title Nasyid musyik training for mosque youth in Dusun III Pondok Pasar IV, Damuli Kebun Village, to provide useful knowledge for mosque youth.
\end{abstract}

Keyword: Music, Nasyid

\begin{abstract}
Abstrak
Indonesia memiliki banyak kebudayan, hampir disetiap daerahnya memiliki kebudayaan dan adat istiadat yang berbeda. Labuhanbatu Utara merupakan salah satu daerah di Sumatera Utara yang memiliki 8 kecamatan. Pada kecamatan Kualuh Selatan memiliki kebiasaan untuk menyanyikana nasyid pada acara-acara tententu dan istimewa. Nasyid adalah salah satu seni Islam dalam bidang seni suara. Biasanya merupakan nyanyian yang bercorak Islam dan mengandungi kata-kata nasihat, kisah para nabi, memuji Allah, dan yang sejenisnya. Biasanya nasyid dinyanyikan secara acappela dengan hanya diiringi gendang. Program pengabdian pada masyarakat kuliah kerja nyata pemberdayaan masyarakat tahun 2019 dengan judul pelatihan musyik nasyid kepada remaja mesjid di Dusun III Pondok Pasar IV Desa Damuli Kebun berguna untuk memberikan pengetahuan yang bermanfaat untuk para remaja mesjid.
\end{abstract}

Kata Kunci: Musik, Nasyid

\section{PENDAHULUAN}

Pemberdayaan Masyarakat adalah proses pembangunan di mana masyarakat berinisiatif untuk memulai proses kegiatan sosial untuk memperbaiki situasi dan kondisi diri sendiri. Pemberdayaan masyarakat akan sukses atau dapat terjadi apabila warga ikut berpartisipasi.

Pemberdayaan masyarakat yang diangkat ialah memberikan penyuluhan tentang musik nasyid pada Labuhanbatu Utara Kabupaten Kualuh Selatan Desa Damuli Kebun. Nasyid adalah salah satu seni Islam dalam bidang seni suara. Biasanya merupakan nyanyian yang bercorak Islam dan mengandungi kata-kata nasihat, kisah para nabi, memuji Allah, dan yang sejenisnya. Biasanya nasyid dinyanyikan secara acappela dengan hanya diiringi gendang. Metode ini muncul karena banyak ulama Islam yang melarang penggunaan alat musik kecuali alat musik perkusi. Nasyid mulai masuk ke Indonesia sekitar era tahun 80 -an. Perkembangannya pada awalnya dipelopori oleh aktivis-aktivis kajian Islam yang mulai tumbuh di kampus-kampus pada masa itu. Pada awalnya yang dinyanyikan adalah syair-syair asli berbahasa Arab. Namun akhirnya berkembang dengan adanya nasyid berbahasa Indonesia dan dengan tema yang semakin luas (tidak hanya tema syahid 
dan jihad). Biasanya nasyid dinyanyikan dalam pernikahan, maupun perayaan hari besar umat Islam.

Kecamatan Kualuh Selatan khususnya Desa Damuli Kebun memiliki sumber daya potensi besar untuk mampu memperdalam musik Nasyid. Bayaknya pemuda-pemudi yang dapat menjadi roda penggerak dan pengembang budaya Nasyid di lingkungan Desa Damuli Kebun akan tetapi saat ini hanya beberapa pemuda-pemudi yang mendalami dan melestarikan musik Nasyid. Dan juga tidak adanya pelatih sehingga kurangnya pengetahuan para pemuda tentang teori dan praktek musik nayid. Sehingga masalah ini menjadi point yang mendasar untuk diselenggarakannya penyuluhan tentang musik Nasyid.

Penyuluhan ini diselenggarakan dengan tujuan membantu para pemuda untuk lebih mendalami musik Nasyid baik secara teori maupun prakteknya, dan dengan adanya penyuluhan ini diharapkan pemuda-pemudi Desa Damuli Kebun lebih tertarik lagi untuk belajar dan mengenal musik Nasyid.

\section{METODE PELAKSANAAN}

Kegiatan pengabdian ini dilakukan dalam 2 tahap yaitu tahap pertama penyuluhan dan dilanjutkan dengan latihan pada remaja yang mengikuti Nasyid untuk praktek secara langsung. Pada tahap pertama dilakukan dengan metode ceramah, diskusi dan tanya jawab. Seluruh peserta dapat mengajuann berbagai pertanyaan tentang Nasyid yang masih belum dan kurang dipahami.

Pada tahap kedua penyuluh terjun langsung melakukan pelatihan ke pemuda tentang teknik dan aturan Nasyid yang baik dan benar, sehingga natinya dapat dipraktekkan secara terus menerus dan menjadi bekal untuk remaja yang mengikuti Nasyid. Dengan berbekal pengetahuan itu dapat mnejadi modal mereka untuk mengikuti berbagai lomba Nasyid.

Jadwal kegiatan pengabdian masyarakat seperti berikut ini.

Tabel 2.1. Jadwal Kegiatan

\begin{tabular}{lllllll}
\hline No & \multicolumn{1}{c}{ Nama Kegiatan } & \multicolumn{5}{c}{ Minggu Ke- } \\
\cline { 3 - 7 } & & & & & \\
\cline { 3 - 7 } & & & & & & \\
1. & Penyusunan Materi & & & & \\
2. & Penentuan Jadwal Penyuluhan dan Koordinasi & & & & & \\
3. & Pelaksanaan Penyuluhan & & & & & \\
4. & Evaluasi dan Penyusunan Laporan & & & & & \\
\hline
\end{tabular}

Adapun tahapan yang dilakukan pembelajaran musik nasyid ialah:

1. Mengadakan pelatih yang berkompeten dalam permainan Nasyid.

2. Memberi pengarahan untuk melihat channel youtobe Nasyid "Bang Show_Ma" yang sudah sangat berkompeten dan telah menuai banyak prestasi.

3. Memberi penyuluhan kepada setiap anggota kelompok Nasyid Al-munawarah tentang pentingnya melestarikan Nasyid yang merupakan salah satu budaya Islam.

4. Mengajak masyakat sekitar untuk lebih memperhatikan maupun mengapresiasi berupa semangat kepada Nasyid Al-munawarah karena merupakan bagian dari kebanggaan Desa Damuli Kebun dusun III.

5. Mengadakan penyuluhan terkait bagaimana cara bermain alat musik Nasyid yang baik dan benar.

6. Membentuk ciri khas Nasyid Al-munawarah seperti alat musik unik tambahan. 


\section{HASIL DAN PEMBAHASAN}

Sampai saat ini kami telah melakukan seluruh kegiatan pokok pengabdian masyarakat di Desa Damuli Kebun, rincian kegiatan tersebut seperti memberikan sosialisasi penyuluhan tentang metode dan cara belajar bermain musik nasyid dengan baik dan benar. Penyuluhan dilakukan di tempat latihan kelompok nasyid Al-Munawarah pada tanggal 5 Agustus 2019 bersama pemudapemudi anggota kelompok Nasyid Al-Munawarah. Metode penyuluhan yang dilakukan dengan cara ceramah dan diteruskan dengan tanya jawab. Materi yang diberikan lebih kepada dasar bermain dan pola rithm musik nasyid, sehingga anggota Nasyid Al-Munawarah memiliki dasar yang bagus untuk bermain musik. Kurangnya fasilitas yang mendukung untuk anggota lebih mengenal dan mendalami musik nasyid, dan juga dikarenakan keterbatas waktu untuk memberikan pelatihan secara intensif dan kontinu kami memberikan solusi alternatif pembelajaran dengan menggunakan media online yang dapat diakses dengan mudah seperti youtube. Melalui channel youtube Bang Show_Ma dan dengan belajar secara mandiri (otodidak) anggota Nasyid AlMunawarah menjadi lebih paham lagi akan teknik dan melodi musik nasyid.

Selain memberikan sosialisasi penyuluhan bagaimana cara bermain musik nasyid dengan baik dan benar, kami juga melakukan praktek secara langsung. Praktek langsung dilakukan setelah pemberian materi. Praktek bermain alat musik nasyid dilakukan secara bersama-sama baik dosen maupun anggota Nasyid Al-Munawarah, dengan begitu para anggota Nasyid Al-Munawarah dapat cara bermain alat nasyid dengan benar dan apabila ada yang melakukan kesalahan dapat langsung diperbaikan cara bermainnya sehinggan menjadi lebih baik lagi. Dokumentasi selama kegiatan dapat dilihat dibawah.

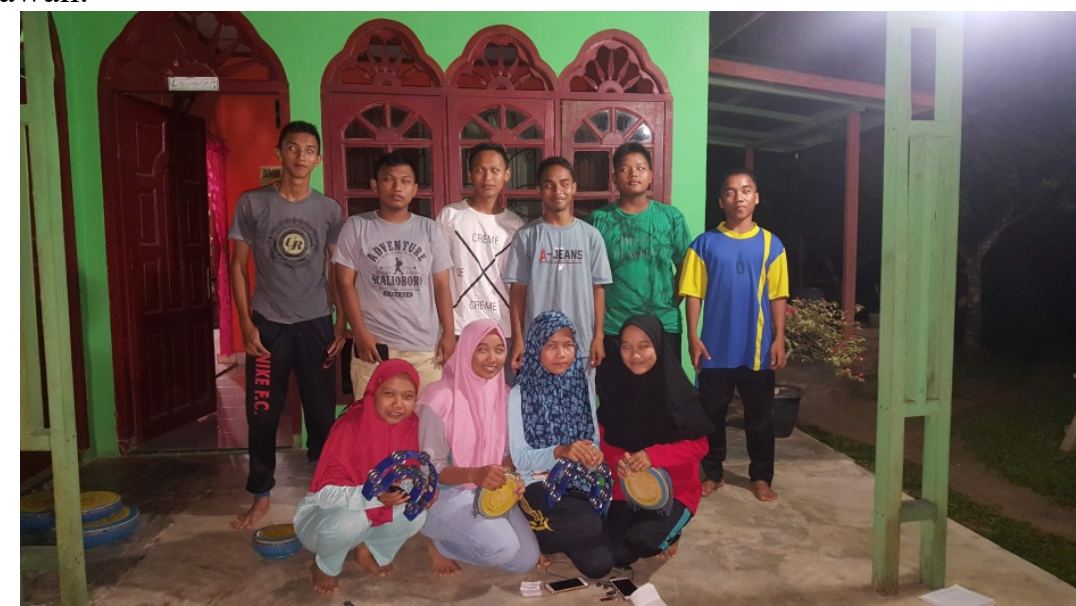

Gambar 3.1. Remaja mesjid yang melestarikan musik nasyid

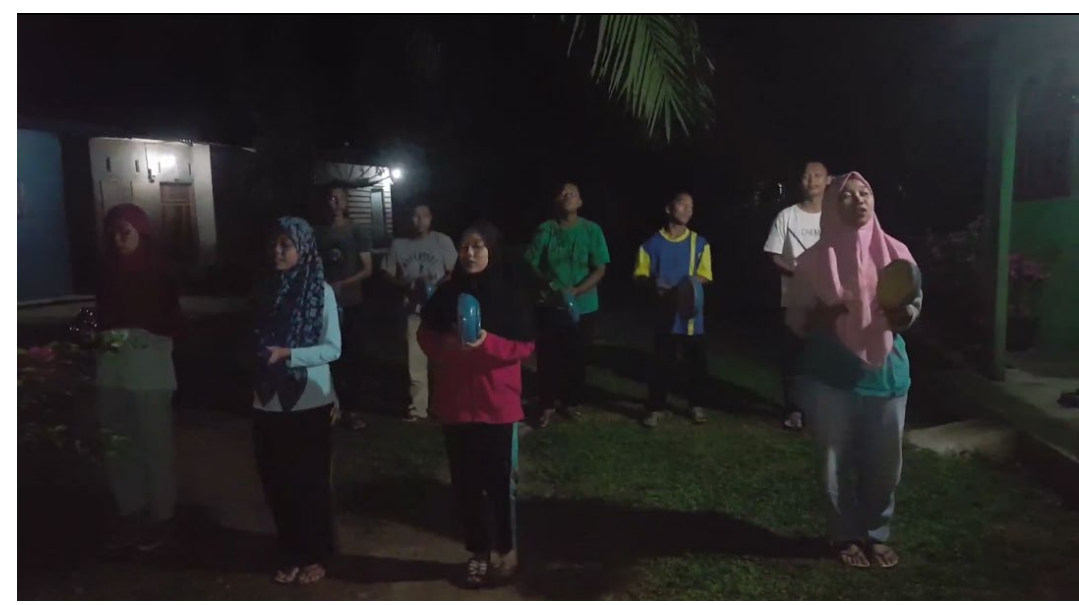

Gambar 3.2 Remaja mesjid yang sedang berlatih musik nasyid 


\section{KESIMPULAN}

Diharapkan dengan adanya penyuluhan dan praktek pembelajaran musik nasyid di Desa Damuli Kebun kepada anggota Nasyid Al-Munawarah dapat memberikan perubahan yang positif, seperti anggota Nasyid Al-Munawarah mampu memainkan pola rithm nasyid dengan baik dan benar, mampu mengaransemen lagu nasyid, dan mampu mengikuti tutorial yang ada di channel youtube secara mandiri dari Bang Show_ma..

\section{UCAPAN TERIMAKASIH}

Pada kesempatan ini kami mengucapkan terimakasih kepada Rektor Universitas Sumatera Utara, Ketua dan Sekretaris Lembaga Pengabdian Pada Masyarakat USU, Dekan Fakultas Ilmu Budaya USU, dan pegawai LPPM yang banyak membatu baik moral maupun materiil.

\section{DAFTAR PUSTAKA}

Tim LPPM. 2019. Kumpulan Makalah Pembekalan Kuliah Kerja Nyata (KKN) USU. Medan: Lembaga Penelitian dan Pengabdian kepada Masyarakat Universitas Sumatera Utara

Wikipedia. 2019. Nasyid. [online]. Tersedia: https://id.Wikipedia.org/wiki/Nasyid [5 September 2019] 